\title{
Is Postoperative Pain Different in the MICS CABG Cohort V. the Traditional Sternotomy Cohort Study?
}

\author{
Bradley C Tenny* and Jeko M Madjarov \\ Sanger Heart and Vascular Institute, Atrium Health, USA \\ *Corresponding author: Tenny, Bradley C, Sanger Heart and Vascular Institute, Atrium Health, Charlotte, NC USA
}

\section{ARTICLE INFO}

Received: 幽 July 16, 2020

Published: 幽 August 05, 2020

Citation: Bradley CT, Jeko MM. Is Postoperative Pain Different in the MICS CABG Cohort V. the Traditional Sternotomy Cohort Study?. Biomed J Sci \& Tech Res 29(2)2020. BJSTR. MS.ID.004785.

Purpose: To determine whether a minimally invasive approach to coronary artery bypass surgery substantially impacts postoperative pain levels.

\author{
ABSTRACT
}

Background: Within the cardiothoracic surgical population postoperative pain is a known phenomenon with varying levels of severity, ranging from minimal to severe discomfort. Minimally invasive cardiac surgery (MICS) has been around since 1995, however there remain few studies that tackle the comparison of pain between this approach versus the "traditional" sternotomy approach. Our study attempts to further the knowledge surrounding MICS, and possibly improve upon the concept of postoperative pain in the cardiac surgical patient.

Methods: To adequately assess postoperative pain in the coronary artery bypass surgical population a multicentered retrospective chart review was carried out; the study utilized a nonexperimental comparative descriptive study design. The retrospective review was conducted over a six-month time frame, proceeding from June 2017 through November 2017, at two hospitals within the same organization. The data collection process began in late December of 2017 and carried through until January of 2018. The assessment of postop pain was performed by using a standard 11-point numeric rating scale/likert scale on post extubation day one and the day of discharge.

Results: Stratifying for a length of stay less than or equal to 6 days, the mean reported pain levels on post extubating day one and on the day of discharge were 8.3 and 3.9 for the sternotomy sample group, and 8.06 and 2.5 for the MICS group. The associated p-value for the day of discharge was 0.0196 , which was determined to be statistically significant.

Conclusions: Our study found that MICS patients report a statistically significant lower pain on the day of discharge in comparison to the patients who undergo traditional sternotomy.

\section{Introduction}

Within the cardiothoracic surgical population postoperative pain is a known phenomenon with varying levels of severity, ranging from minimal to severe discomfort. The quantification of this reported phenomenon in coronary artery bypass graft surgical (CABG) patients has been carried out in the assessment of the traditional sternotomy approach, but not so in the comparison to the limited anterior thoracotomy incision required for minimally invasive cardiac surgery. In fact, during our pre-study literature search we found limited data which helps to support the gestalt in comparing pain between these two operative techniques (Baishya, George and Krishnamoorthy). This is a worrisome fact given that the estimated societal impact of pain is in the hundred billion in the
U.S., and that postoperative pain is surely an important component of this (Institute of Medicine) [1].

\section{Methods}

To adequately assess postoperative pain in the coronary artery bypass surgical population a multicentered retrospective chart review was carried out; the study utilized a nonexperimental comparative descriptive study design. It is important to note that all this study's work has been reported in line with the STROCSS criteria. The hospital institutional review board's approval (IRB file \#09-17-29E) was obtained prior to the data collection process. The retrospective review was conducted over a six-month time 
frame, consisting from June 2017 through November 2017, at two hospitals within the same organization. One of the hospitals was a level one trauma center within the epicenter of a major southeastern metropolitan area, and the second was a community hospital within the suburbs of the same city's geographical limits. The data collection process began in late December of 2017 and concluded in January of 2018 [2]. The process included systematically analyzing the following medical record information for all patients: the preoperative history and physical note, preoperative consultation notes, the operative note, and lastly the postoperative pain assessment administered by the nursing staff post procedure. The postoperative pain assessment was performed using the standard 11-point numeric rating scale (Elfering and Haefeli, example in (Appendix).

\section{1) Example of a 9-point numeric pain scale:}

\section{No pain} mild

No pain

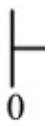
1

\section{2}

moderate severe

Pain as bad as it could be

Retrieved from https://www.ncbi.nlm.nih.gov/pmc/articles/PMC3454549. Note that our study consisted of using the standard a 11-point numeric scale (0-10).

\section{Appendix A.}

The highest reported/recorded pain level on the day post extubation, and the highest reported/recorded pain level on the day of discharge were chosen prior to commencement of the study (Table 1). Inclusion for participation in the retrospective review was limited to patients who had an isolated coronary artery bypass surgery, either minimally invasive or a "traditional" sternotomy, within the predetermined six-month time frame (Figure 1). The exclusion criteria for the review consisted of the following: documented history of any chronic pain syndromes requiring active treatment, the "relative" recent requirement of narcotic analgesic use for pain relief prior to operation, any CABG operation that inadvertently resulted in an operative surgical complication, and patient cases that resulted in readmissions within 30 days from surgery. These inclusion and exclusion criteria were set prior to the data collection process. Of note, surgical complications that excluded patients included delayed sternal closure (4) and sternal wound infection (1). The other exclusion criteria resulted in a total 28 patients being omitted from the statistical testing for a total of 179 patients for analysis (Tables $2 \& 3$ ). After the conclusion of data collection multiple statistical tests were then performed to determine where there were any significant differences among the two sample groups [3,4].

Table 1: The frequency procedure/demographic data outputted by the statistical analysis software (S.A.S.).

\begin{tabular}{|c|c|c|c|}
\hline \multirow{2}{*}{ MICS } & \multicolumn{2}{|c|}{ Table of MICS by gender } \\
\hline \multirow{3}{*}{ no } & F & Mender & Total \\
\cline { 2 - 4 } & 27 & 101 & 128 \\
& 15.08 & 56.42 & 71.51 \\
\hline \multirow{2}{*}{ Yes } & 21.09 & 78.91 & 51 \\
& 77.14 & 70.14 & 28.49 \\
\hline \multirow{2}{*}{ Total } & 8 & 43 & 179 \\
& 4.47 & 24.02 & 100 \\
\hline
\end{tabular}


Table 2: Reported frequency of levels of pain on post extubation day one by either sample group (MICS vs Sternotomy).

\begin{tabular}{|c|c|c|c|c|c|c|c|c|c|}
\hline \multicolumn{10}{|c|}{ Table of MICS by PED1 } \\
\hline \multirow{2}{*}{ MICS } & \multicolumn{9}{|c|}{ PED1 } \\
\hline & 3 & 4 & 5 & 6 & 7 & 8 & 9 & 10 & Total \\
\hline \multirow{4}{*}{ no } & 1 & 2 & 5 & 4 & 16 & 35 & 24 & 41 & 128 \\
\hline & 0.56 & 1.12 & 2.79 & 2.23 & 8.94 & 19.55 & 13.41 & 22.91 & 71.51 \\
\hline & 0.78 & 1.56 & 3.91 & 3.13 & 12.5 & 27.34 & 18.75 & 32.03 & \\
\hline & 100 & 66.67 & 71.43 & 44.44 & 66.67 & 70 & 80 & 74.55 & \\
\hline \multirow{4}{*}{ Yes } & 0 & 1 & 2 & 5 & 8 & 15 & 6 & 14 & 51 \\
\hline & 0 & 0.56 & 1.12 & 2.79 & 4.47 & 8.38 & 3.35 & 7.82 & 28.49 \\
\hline & 0 & 1.96 & 3.92 & 9.8 & 15.69 & 29.41 & 11.76 & 27.45 & \\
\hline & 0 & 33.33 & 28.57 & 55.56 & 33.33 & 30 & 20 & 25.45 & \\
\hline \multirow{2}{*}{ Total } & 1 & 3 & 7 & 9 & 74 & 50 & 30 & 55 & 179 \\
\hline & 0.56 & 1.68 & 3.91 & 5.03 & 13.41 & 27.93 & 16.76 & 30.73 & 100 \\
\hline
\end{tabular}

Table 3: Reported frequency of levels of pain on the day of discharge by either sample group (MICS vs Sternotomy).

\begin{tabular}{|c|c|c|c|c|c|c|c|c|c|}
\hline \multicolumn{10}{|c|}{ Table of MICS by PED1 } \\
\hline \multirow{2}{*}{ MICS } & \multicolumn{9}{|c|}{ DOD } \\
\hline & $\mathbf{0}$ & 1 & 2 & 3 & 4 & 5 & 6 & 7 & 8 \\
\hline \multirow{4}{*}{ no } & 50 & 2 & 4 & 2 & 5 & 11 & 15 & 14 & 15 \\
\hline & 27.93 & 1.12 & 2.23 & 1.12 & 2.79 & 6.15 & 8.38 & 7.82 & 8.38 \\
\hline & 39.06 & 1.56 & 3.13 & 1.56 & 3.91 & 8.59 & 11.72 & 10.94 & 11.72 \\
\hline & 67.57 & 100 & 100 & 100 & 100 & 55 & 71.43 & 73.68 & 78.95 \\
\hline \multirow{4}{*}{ Yes } & 24 & 0 & 0 & 0 & 0 & 9 & 6 & 5 & 4 \\
\hline & 13.41 & 0 & 0 & 0 & 0 & 5.03 & 3.35 & 2.79 & 2.23 \\
\hline & 47.06 & 0 & 0 & 0 & 0 & 17.65 & 11.76 & 9.8 & 7.84 \\
\hline & 32.43 & 0 & 0 & 0 & 0 & 45 & 28.57 & 26.32 & 21.05 \\
\hline Total & 7 & 2 & 4 & 2 & 5 & 20 & 21 & 19 & 19 \\
\hline
\end{tabular}

Results

\section{The FREQ Procedure}

\begin{tabular}{|c|c|c|c|c|}
\hline \multirow{3}{*}{$\begin{array}{l}\text { Frequency } \\
\text { Percent } \\
\text { Row Pct } \\
\text { Col Pct }\end{array}$} & \multicolumn{4}{|c|}{ Table of MICS by gender } \\
\hline & \multirow[b]{2}{*}{ MICS(MICS) } & \multicolumn{3}{|c|}{ gender(gender) } \\
\hline & & f & m & Total \\
\hline & no & \begin{tabular}{r|}
27 \\
15.08 \\
21.09 \\
77.14
\end{tabular} & $\begin{array}{r}101 \\
56.42 \\
78.91 \\
70.14\end{array}$ & $\begin{array}{r}128 \\
71.51\end{array}$ \\
\hline & yes & $\begin{array}{r}8 \\
4.47 \\
15.69 \\
22.86\end{array}$ & $\begin{array}{r}43 \\
24.02 \\
84.31 \\
29.86\end{array}$ & $\begin{array}{r}51 \\
28.49\end{array}$ \\
\hline & Total & $\begin{array}{r}35 \\
19.55\end{array}$ & $\begin{array}{r}144 \\
80.45\end{array}$ & $\begin{array}{r}179 \\
100.00\end{array}$ \\
\hline
\end{tabular}

Figure 1.
The mean and median of reported pain for post-extubation day one (PED1) in the MICS sample group was 8.11 and 8.0 respectively. The mean and median of reported pain for day of discharge (DOD) was determined to be 3.47 and 5.0 respectively. Conversely, the mean and median PED1 pain was 8.42 and 9.0 for the traditional sternotomy sample population. DOD pain for the traditional sternotomy sample population was found to be 3.85 and 5.0 (Table 4): SAS output below. MICS= no infers the traditional sternotomy sample group). With the median pain levels at PED1 and DOD known for both sample groups the Wilcoxon rank sum test was then performed to assess for any statistically significant difference. This nonparametric test was chosen given the unknown population variance of coronary artery bypass patients in regard to reported postoperative pain. The returned p-values for the PED1 and DOD between the two sample groups were 0.272 and 0.478 respectively (Table 5). 
Table 4: Measures of central tendency regarding reported pain on both post extubation day 1 and the day of discharge. S.A.S. output.

\begin{tabular}{|c|c|c|c|c|c|c|c|}
\hline \multicolumn{8}{|c|}{ MICS= No } \\
\hline Variable & Label & N & Mean & Std Dev & Lower Quartile & Median & Upper Quartile \\
\hline PED1 & PED1 & 128 & 8.421875 & 1.534944 & 8 & 9 & 10 \\
\hline DOD & DOD & 128 & 3.8515625 & 3.5094694 & 0 & 5 & 7 \\
\hline
\end{tabular}

\begin{tabular}{|c|c|c|c|c|c|c|c|}
\hline \multicolumn{9}{|c|}{ MICS= Yes } \\
\hline Variable & Label & N & Mean & Std Dev & Lower Quartile & Median & Upper Quartile \\
\hline PED1 & PED1 & 51 & 8.1176471 & 1.5703128 & 7 & 8 & 10 \\
\hline DOD & DOD & 51 & 3.47891428 & 3.4891428 & 0 & 5 & 6 \\
\hline
\end{tabular}

Table 5: Measures of central tendency, now stratified by length of stay, for both post extubation day 1 and the day of discharge. S.A.S. output.

\begin{tabular}{|c|c|c|c|c|c|c|c|}
\hline \multicolumn{1}{|c|}{ MICS= No } \\
\hline Variable & Label & N & Mean & Std Dev & Lower Quartile & Median & Upper Quartile \\
\hline PED1 & PED1 & 70 & 8.3714286 & 1.5052702 & 8 & 8 & 10 \\
\hline DOD & DOD & 70 & 3.9714286 & 3.4681634 & 0 & 5 & 7 \\
\hline
\end{tabular}

\begin{tabular}{|c|c|c|c|c|c|c|c|}
\hline \multicolumn{10}{|c|}{ MICS= Yes } \\
\hline Variable & Label & N & Mean & Std Dev & Lower Quartile & Median & Upper Quartile \\
\hline PED1 & PED1 & 31 & 8.0645161 & 1.6918527 & 7 & 8 & 10 \\
\hline DOD & DOD & 31 & 2.5806452 & 3.2122079 & 0 & 0 & 5 \\
\hline
\end{tabular}

The two sample populations were then stratified based upon length of stay, where those patients who were discharged after postoperative day 6 excluded, in order to remove unaccounted bias in the aforementioned results (please see detailed explanation of 6 day cut exclusion criteria in the discussion section). With a length of stay < or = to 6 days the MICS sample size had decreased to 31 and the traditional sternotomy sample size was now 70 patients

Table 6: The NPAR1WAY procedure performed by S.A.S. Demonstrating the Wilcoxon Rank Sum statistical test. Probability value (" $p$ value") is demonstrated to be statistically significant under the $t$ approximation and by the accompanied graph.

\begin{tabular}{|c|c|c|c|c|c|}
\hline \multicolumn{7}{|c|}{ Wilcoxon Scores (Rank Sums) for variable DOD classified by Variable MICS } \\
\hline MICS & N & Sum of Scores & Expected Under H0 & Std Dev Under H0 & Mean Score \\
\hline Yes & 31 & 1309.0 & 1581.0 & 130.125969 & 42.225806 \\
\hline No & 70 & 3842.0 & 3570.0 & 130.125969 & 54.885714 \\
\hline \multicolumn{7}{|c}{ Average scores were used for ties. } \\
\hline
\end{tabular}

\begin{tabular}{|c|c|c|c|c|c|}
\hline \multicolumn{2}{|c|}{ Wilcoxon Two Sample Test } \\
\hline \multirow{2}{*}{ Statistic } & $\mathbf{Z}$ & $\operatorname{Pr}<\mathbf{Z}$ & $\operatorname{Pr}>\mathbf{Z}$ & \multicolumn{2}{|c|}{ t test approximation } \\
\cline { 3 - 6 } & & & & $\operatorname{Pr}<\mathbf{Z}$ & 0.0196 \\
\hline 1309.000 & -2.0903 & 0.0183 & 0.0366 & 0.0391 \\
\hline
\end{tabular}

\begin{tabular}{|c|c|c|}
\hline \multicolumn{2}{|c|}{ Kruskal-Wallis Test } \\
\hline Chi-Square & DF & PR $>$ ChiSq \\
\hline 4.3693 & 1 & 0.0366 \\
\hline
\end{tabular}




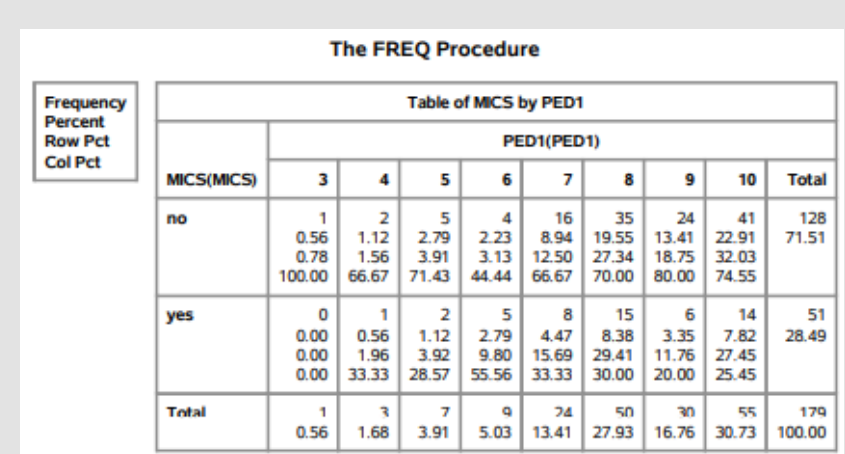

Figure 2.

\section{Discussion}

Regarding the methodology, the highest reported pain level rather than the frequency of narcotic use, or average daily pain level was utilized due to the possibility of nonsynchronous assessments performed by the nursing staff. Variable assessments of postoperative pain would surely be a confounding variable for this study. For illustration, one nurse may have simply inquired about postoperative pain more frequently than their counterpart; choosing a static outcome prevented this possible bias based upon frequency of assessment. Lastly, utilizing reported pain via a Likert scale prevented subjective interpretation by the nursing staff in comparison to if had the "faces scale" been used. The faces scale is a pain measurement device primarily used for pediatric and nonverbal patients. Stratification of our two sample groups by length of stay was performed to account for patients who may have had minor intraoperative deviations from the standard of care, such as prolong cardiopulmonary bypass times that are known to impact length of stay as well as postop discomfort (Madhaven, Chan and Tan), that were not initially accounted for in the study's design. Furthermore, excluding patients who had 7 or more days in the hospital allowed for more a homogenous comparison between groups. For instance, it removed outliers who may have remained inpatient for two weeks due to some aberrant or rare issue. The average day of discharge for cardiac surgery patients is in the morning on postoperative day 5 (Almasharfi, Alsabti and Mukaddirov) (Figure 3 \& 4) [7].

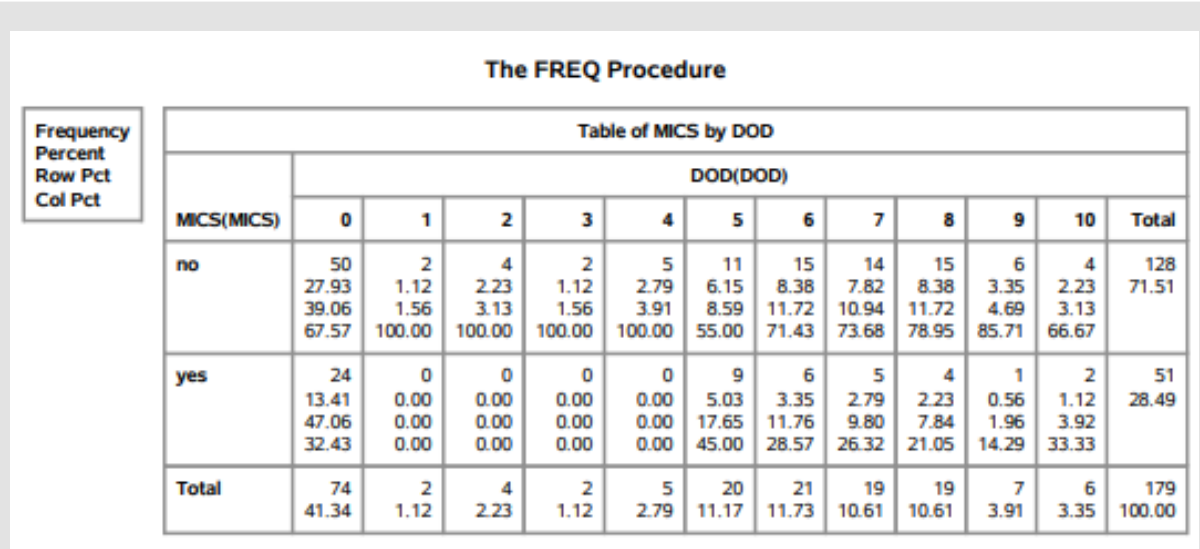

Figure 3.

\section{The MEANS Procedure}

MICS=no

\begin{tabular}{|l|l|r|r|r|r|r|r|}
\hline Variable & Label & N & Mean & Std Dev & $\begin{array}{r}\text { Lower } \\
\text { Quartile }\end{array}$ & $\begin{array}{r}\text { Upper } \\
\text { Median }\end{array}$ & $\begin{array}{r}\text { Quartile } \\
\hline \text { PED1 }\end{array}$ \\
PED 1 & 128 & 8.4218750 & 1.5349440 & 8.0000000 & 9.0000000 & 10.0000000 \\
\hline & DOD & 128 & 3.8515625 & 3.5094694 & 0 & 5.0000000 & 7.0000000 \\
\hline
\end{tabular}

MICS=yes

\begin{tabular}{|l|l|r|r|r|r|r|r|}
\hline Variable & Label & N & Mean & Std Dev & $\begin{array}{r}\text { Lower } \\
\text { Quartile }\end{array}$ & $\begin{array}{r}\text { Upper } \\
\text { Median }\end{array}$ \\
\hline PED1 & PED1 & 51 & 8.1176471 & 1.5703128 & 7.0000000 & 8.0000000 & 10.0000000 \\
DOD & DOD & 51 & 3.4705882 & 3.4891428 & 0 & 5.0000000 & 6.0000000 \\
\hline
\end{tabular}

Figure 4. 
By including those patients who remained in the hospital 6 days or less after surgery, a total of 7 days inpatient, allowed for the analysis of the prototypical patient while excluding those who had a more atypical hospital course. Lastly, it is important to note the single divergence in postoperative management between our two sample groups causing possible bias [8-10]. Within our organization the current practice for MICS patients is to receive an anesthetic infusion for an average of 24 hours postop within the surgical site. This adjunct use of a bupivacaine wound catheter was utilized in approximately $95 \%$ of all MICS patients in this chart review. This near unanimous utilization made stratification or statistical testing impossible to remove its effects from influencing the results. However, bupivacaine has a reported half-life of only 3.1 hours and a duration of action ranging from 6-7hrs before the analgesic effects wear off (Collins, Mahabir and Song). Given that this therapeutic was discontinued by postoperative day 2 it most likely would not have substantially affected the found difference in the reported pain level on the day of discharge (Figure $5 \& 6$ ).

\section{The MEANS Procedure}

MICS=no

\begin{tabular}{|l|l|r|r|r|r|r|r|}
\hline Variable & Label & N & Mean & Std Dev & $\begin{array}{r}\text { Lower } \\
\text { Quartile }\end{array}$ & $\begin{array}{r}\text { Mpper } \\
\text { Muartile }\end{array}$ \\
\hline PED1 & PED1 & 70 & 8.3714286 & 1.5052702 & 8.0000000 & 8.0000000 & 10.0000000 \\
DOD & DOD & 70 & 3.9714286 & 3.4681634 & 0 & 5.0000000 & 7.0000000 \\
\hline
\end{tabular}

MICS=yes

\begin{tabular}{|l|l|r|r|r|r|r|r|}
\hline Variable & Label & N & Mean & Std Dev & $\begin{array}{r}\text { Lower } \\
\text { Quartile }\end{array}$ & Median & $\begin{array}{r}\text { Upper } \\
\text { Quartile }\end{array}$ \\
\hline PED1 & PED1 & 31 & 8.0645161 & 1.6918527 & 7.0000000 & 8.0000000 & 10.0000000 \\
DOD & DOD & 31 & 2.5806452 & 3.2122079 & 0 & 0 & 5.0000000 \\
\hline
\end{tabular}

Figure 5.

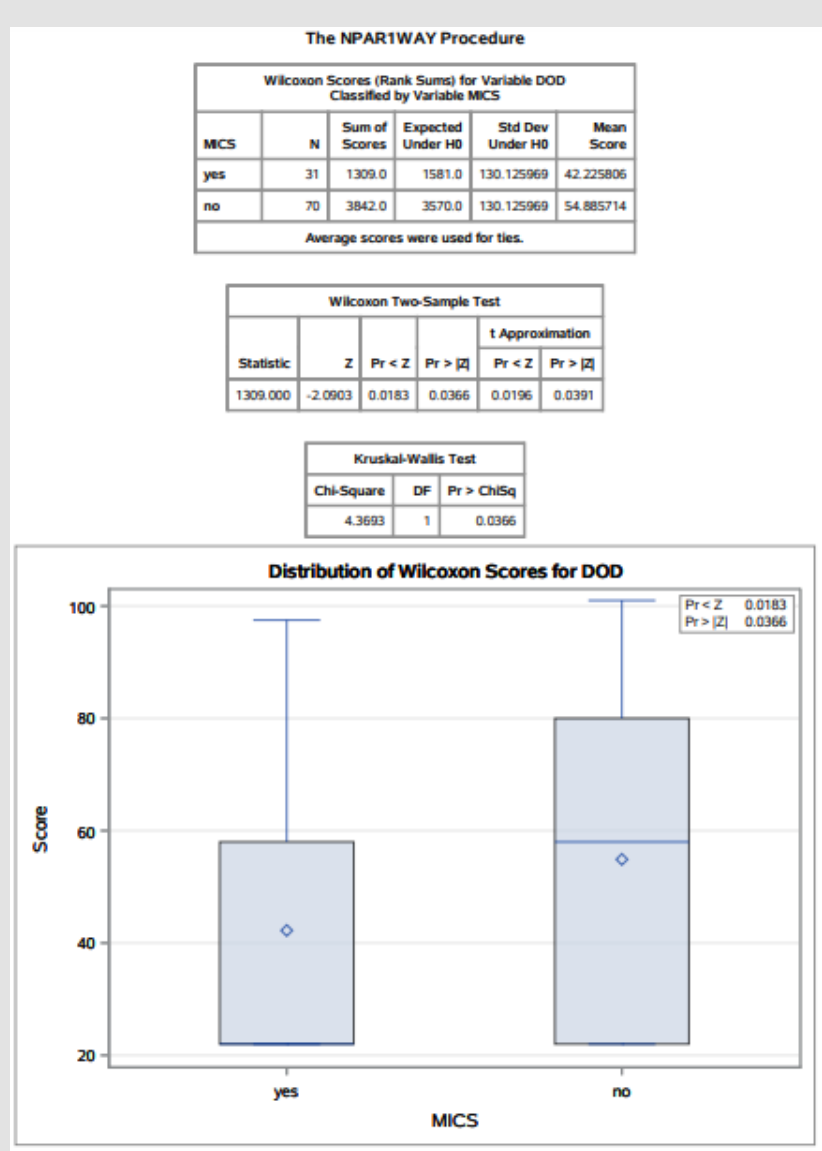

Figure 6. 


\section{Conclusion}

Our study found that MICS patients report a statistically significant lower pain on the day of discharge in comparison to the patients who undergo traditional sternotomy. This is not to say that one operative technique is more superior than the other, especially given that certain patient characteristics must be met to justify a minimally invasive approach, however, our findings support a more serious consideration for minimally invasive cardiac surgery if deemed a viable option and should encourage further research on these two operative techniques

\section{References}

1. Agha RA, Borrelli MR, Vella-Baldacchino M, Thavayogan R and Orgill DP, et al. (2017) The STROCSS Statement: Strengthening the Reporting of Cohort Studies in Surgery. International Journal of Surgery 46: 198-202.

2. Rogers CA1, Pike K, Angelini GD, Reeves BC, Glauber M, et al. (2013) An open randomized controlled trial of median sternotomy versus anterolateral left thoracotomy on morbidity and health care resource use in patients having off-pump coronary artery bypass surgery: The Sternotomy Versus Thoracotomy (STET) trial. Journal of Thoracic Cardiovascular Surgery 1-9.

3. Ahmed Almashrafi, Hilal Alsabti, Mirdavron Mukaddirov, Baskaran Balan, Paul Aylin, et al. Factors associtated with prolonged length of stay following cardiac surgery in a major referral hospital in Oman: a retrospective observational study. British Medical Journal.

ISSN: $2574-1241$

DOI: $10.26717 / B J S T R .2020 .29 .004785$

Bradley C Tenny. Biomed J Sci \& Tech Res

(C) This work is licensed under Creative

Submission Link: https://biomedres.us/submit-manuscript.php
4. Jitumoni Baishya, Antony George, Jayaprakash Krishnamoorthy, Geetha Muniraju, Murali Chakravarthy, et al. (2017) Minimally Invasive Compared to Conventional Approach for Coronary Artery Bypass Grafting Improves Outcomes. Annals of cardiac anesthesia: 57-60.

5. Collins, James, Raman Mahabir and Juhee Song (2013) Onset and duration of intradermal mixtures of bupivacaine with epinephrine. Canada Journal of Plastic Surgery: 51-53.

6. Dieberg, King, Smart (2016) Minimally invasive cardiac surgery: A systematic review and meta-analysis. International Journal of Cardiology: 554-560

7. Elfering, A and M Haefeli (2006) Pain Assessment. European Spine Journal: S17-24.

8. Madhaven S, Siew pang C, Wei-Chuan T, Jolane E, Bowen Li, et al. (2017) Cardiopulmonary Bypass Time: Every Minute Counts. Bethesda: Journal of Cardiovascular Surgery 59(2).

9. Rijkenberg S, Stilma W, Bosman RJ, Van der Meer, Van deer Voort (2017) Pain measurement in mechanically ventilated patients after cardiac surgery: Comparison of the behavioral pain scale (BPS) and the criticalcare pain observational tool (CPOT). Journal of Cardiothoracic and Vascular Anesthesia (2017): 1227-1234.

10. Marek Zubrzycki, Andreas Liebold, Christian Skrabal, Helmut Reinelt, Mechthild Ziegler et al. (2018) Assessment and pathophysiology of pain in cardiac surgery. Journal of Pain Research 11: 1599-1611.

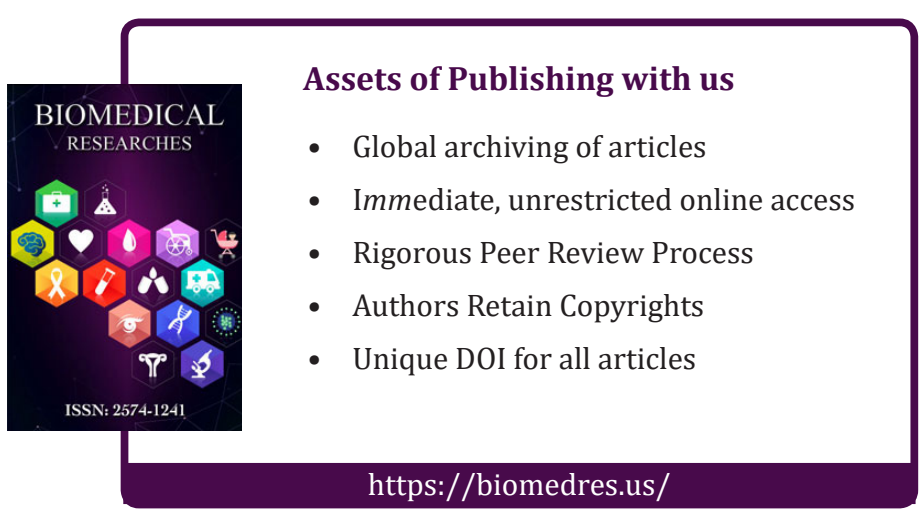

